\title{
PUZZLE SEBAGAI MEDIA BERMAIN UNTUK MELATIH KEMANDIRIAN ANAK USIA DINI
}

\author{
Lusi Nuranisa ${ }^{1}$, Mesi Triani ${ }^{2}$, Wida Austin Hidayah $^{3}$, Putri Mei Aurelia ${ }^{4}$, \\ Dede Anwar Sanusi ${ }^{5}$, Nunik Nasyatul Khoeriyah ${ }^{6}$, Elfan Fanhas Fatwa \\ Khomaeny $^{7}$ \\ 1-7 Universitas Muhammadiyah Tasikmalaya
}

\author{
Email : lusynuranisa@gmail.com ${ }^{1}$, mesitriani@gmail.com² ${ }^{2}$, widaaustin12@gmail.com³ \\ meyaurelia67@gmail.com ${ }^{4}$, dedeanwar056@gmail.com ${ }^{5}$, \\ nuniknasyatul@gmail.com ${ }^{6}$, elfan.fanhas@umtas.ac.id ${ }^{7}$
}

\begin{abstract}
ABSTRAK
Pendidikan karakter merupakan hal penting yang harus di tumbuhkan pada anak usia dini, salah satunya mengenai kemandirian. Anak usia dini merupakan masa yang menjadi dasar pembentukan karakter dan kepribadian anak. Sehingga akan sangat penting bila kemandirian sudah mulai ditumbuhkan sejak dini. Salah satu cara untuk menumbuhkan kemandirian pada anak usia dini bisa dilakukan dengan bermain. Bermain mempunyai arti yang sangat penting bagi anak karena setiap anak mempunyai dorongan untuk bermain dan merupakan suatu kebutuhan untuk seorang anak. Dengan bermain, aspek kemandirian akan didapat dari bagaimana cara anak menyelesaikan sebuah tantangan tanpa harus ketergantungan pada orang lain. Metode bermain yang digunakan yaitu dengan menggunakan media puzzle. Media puzzle adalah media permainan anak yang akan meningkatkan kognitif anak serta akan membantu anak mengembangkan kemampuan kemandirian dalam menyelesaikan masalah. Metode penelitian yang digunakan yaitu dengan studi literatur yang merupakan survei dan pembahasan literatur pada bidang tertentu dari suatu penelitian. Studi ini merupakan gambaran singkat dari apa yang telah dipelajari, argumentasi, dan ditetapkan tentang suatu topik, dan biasanya diorganisasikan secara kronologis atau tematis.
\end{abstract}

Kata Kunci : pendidikan karakter, kemandirian, anak usia dini, puzzle.

\begin{abstract}
Character education is an important thing that should be grown in early childhood, one of which is about independence. Early childhood is the period that became the basis of character formation and personality of children. So it will be very important if the independence has begun to grow early on. One way to cultivate self-reliance in early childhood can be $d$ one by playing. Playing has a very important meaning for the child because every child has a drive to play and is a necessity for a child. By playing, the independence aspect will be gained from how the children solve a challenge without having to depend on others. Playing method used is by using the media puzzle. Media puzzle is a child's game media that will improve children's cognitive and will help children develop the ability of independence in solving problems. The research method used is literature study which is a survey and discussion of literature in certain field of a research. This study is a brief overview of what has been learned, argued, and defined about a topic, and is usually organized chronologically or thematically.
\end{abstract}

Keyword : character, independence, early childhood,puzzle.

\section{PENDAHULUAN}

Anak usia dini adalah manusia yang menuju proses ke tahap selanjutnya dimana dia akan memasuki jenjang pendidikan sekolah dasar. Anak yang akan memasuki pendidikan 
Lusi Nuranisa, Mesi Triani, Wida Austin Hidayah, Putri Mei Aurelia, Dede Anwar Sanusi, Nunik Nasyatul Khoeriyah, Elfan Fanhas Fatwa Khomaeny. PUZZLE SEBAGAI MEDIA BERMAIN UNTUK MELATIH KEMANDIRIAN ANAK USIA DINI. Early Childhood Vol. 2 No. 2a, November 2018

sekolah dasar diharapkan mampu untuk mandiri, tidak lagi menangis jika jauh dari orang tua, mampu bersosialisasi dengan anak lain, dan masih banyak lagi. Akan tetapi fenomena yang terjadi saat ini, anak yang akan memasuki pendidikan sekolah dasar belum dapat dikatakan mandiri, karena ketika anak berada di sekolah terkadang sulit untuk bersosialisasi, tidak percaya diri, dan selalu bergantung pada orang lain khususnya orang tunya sendiri. Hal ini merupakan salah satu contoh dari orang dewasa khususnya orang tua yang belum menerapkan nilai kemandirian sejak usia dini dengan beberapa alasan ketika akan menerapkan aspek kemandirian pada anak, padahal pada usia ini akan menentukan karakater anak dimasa yang akan datang.

Artikel ini akan mengkaji tentang metode yang dapat melatih nilai karakter kemandirian pada anak usia dini dengan menggunakan media puzzle yang tentunya disenangi oleh anakanak.

\section{METODE PENELITIAN}

Metode penilitian menggunakan studi literatur dengan mengumpulkan berbagai sumber yang berkaitan dengan materi menumbuhkan kemandirian pada anak usia dini dengan metode bermain. Sebuah studi literatur merupakan survei dan pembahasan literatur pada bidang tertentu dari suatu penelitian. Studi ini merupakan gambaran singkat dari apa yang telah dipelajari, argumentasi, dan ditetapkan tentang suatu topik, dan biasanya diorganisasikan secara kronologis atau tematis. Menurut
Sugiyono, studi kepustakaan berkiatan dengan kajian teoritis dan referensi lain yang berkiatan dengan nilai, budaya dan norma yang berkembang pada situasi sosial yang diteliti, selian itu studi kepustakaan sangat penting dalam melakukan penelitian, hal ini dikarenakan penelitian tidak akan lepas dari literatur-literatur ilmiah (Sugiyono, 2012:291).

\section{HASIL DAN PEMBAHASAN}

\section{A. Pengertian Anak Usia Dini}

Anak usia dini merupakan sekelompok manusia yang berada dalam proses pertumbuhan dan perkembangan (Aris Priyanto, 2014:2), dalam psikologi perkembangan dan berdasarkan riset neurology, anak usia dini dikatakan sebagai anak yang berumur 0-8 tahun (Dedi Supriadi, 2003:1) dalam Khasanah, dkk (2011). Pertumbuhan dan perkembangannya diperhatikan dengan cara memberikan perlakuan yang berupa pendidikan anak usia dini. Menurut Carol and Nita (1993) dalam Ismatul Hasanah, menyatakan bahwa anak usia dini adalah anak sejak dilahirkan sampai berusia delapan tahun. Dalam rentang waktu itu Seefeldt membagi masing masing tahapan berdasarkan usia yaitu infancy (0-1 tahun), toodler 1-3 tahun, preschool (3-4 tahun), early primary years (5-6 tahun) dan later primary years (7-8 tahun). Masing - masing tahap usia memiliki karakteristik perkembangan yang berbeda antara satu dengan yang lainnya baik secara fisik, sosial emosional (afektif) maupun secara kognitif. 
Lusi Nuranisa, Mesi Triani, Wida Austin Hidayah, Putri Mei Aurelia, Dede Anwar Sanusi, Nunik Nasyatul Khoeriyah, Elfan Fanhas Fatwa Khomaeny. PUZZLE SEBAGAI MEDIA BERMAIN UNTUK MELATIH KEMANDIRIAN ANAK USIA DINI. Early Childhood Vol. 2 No. 2a, November 2018

\section{B. Karakteristik Anak Usia Dini}

Karakteristik anak usia dini menurut Sujiono dalam (Ratna Juita, 2012:4) adalah anak mengira dunia ini penuh dengan hal-hal yang menarik dan menakjubkan, membangun konsep diri melalui interaksi sosial, anak merupakan pribadi yang unik, kaya dengan fantasi, anak senang dengan halhal yang bersifat imajinatif.

\section{Pengertian Pendidikan}

Dalam Kamus Besar Bahasa Indonesia pendidikan diartikan sebagai proses perubahan sikap dan atau laku seseorang atau kelompok orang dalam usaha mendewasakan manusia melalui upaya pengajaran dan pelatihan. Karena anak usia dini merupakan manusia yang belum dewasa dan membutuhkan pendidikan dari orang dewasa untuk mencapai kedewasaanya, maka pendidikan yang diterapkan pada anak harus sesuai dengan perkembangannya.

Menurut Hasyim (2012:7) strategi dalam pembelajaran pada anak usia dini yaitu :

1. Berbasis pada psikologi anak sesuai dengan perkembangan usianya anak.

Pada masa ini, anak sudah dapat dididik baik fisik, intelektual, emosional, bahasa, sosial, bermain dan kepribadiannya yang harus disesuaikan dengan perkembangan jiwanya. Untuk ini pengetahuan seperkembangan jiwanya. Untuk ini pengetahuan secara mendalam tentang psikologis anak mutlak diperlukan.

2. Berbasis pada pandangan bahwa anak masih dalam keadaan lemah, belum dapat menolong dirinya sendiri, butuh perlindungan, kasih sayang, belum dapat bertanggung jawab, dan seterusnya.

3. Berbasis pada pandangan bahwa anak bukanlah manusia dewasa yang berbadan kecil, melainkan makhluk yang memiliki bakat, minat, kecenderungan dan lainnya yang belum tergali.

4. Berbasis pada pandangan bahwa seorang anak lebih suka diperlakukan secara halus dan santun daripada dengan cara kasar. Rasulullah SAW pernah mengingatkan : berhati-hatilah terhadap anak-anak, karena ia ibarat gelas yang mudah pecah.

5. Berbasis pada pandangan, bahwa anak-anak yang berada dalam usia dini adalah anak-anak yang berada dalam usia bermain dan rekreatif.

6. Strategi Islam dalam mendidik anak di usia dini dilakukan dengan dua cara, yaitu secara langsung dan tidak langsung.

Salah satu contoh pendidikan yang diberikan pada anak yaitu pendidikan karakter. Pendidikan karakter adalah tanggungjawab bersama antara keluarga, sekolah, dan masyarakat. Keluarga adalah pusat pendidikan yang pertama dan terpenting, sejak munculnya peradaban manusia hingga sekarang keluarga paling bepengaruh pada perkembangan budi pekerti seorang manusia (Ki Hajar Dewantara, 1977) dalam jurnal (Elfan Fanhas KH, 2017). 
Lusi Nuranisa, Mesi Triani, Wida Austin Hidayah, Putri Mei Aurelia, Dede Anwar Sanusi, Nunik Nasyatul Khoeriyah, Elfan Fanhas Fatwa Khomaeny. PUZZLE SEBAGAI MEDIA BERMAIN UNTUK MELATIH KEMANDIRIAN ANAK USIA DINI. Early Childhood Vol. 2 No. 2a, November 2018

\section{Pengertian Kemandirian}

Pada saat dilahirkan manusia dalam keadaan tidak berdaya, namun dibalik ketidak berdayaannya tersebut menyimpan potensi yang besar untuk dikembangkan untuk berkembang secara wajar, seseorang memerlukan bantuan orang lain guna membimbing dan mengarahkan perkembangan potensi tersebut. Bantuan orang lain tersebut dapat berasal dari keluarga, lembaga pendidikan, dan masyarakat luas.

Menurut Erikson dalam (Desmita, 2011) kemandirian adalah usaha untuk melepaskan diri dari orang tua dengan maksud untuk menemukan dirinya melalui proses mencari identitas ego, yaitu merupakan perkembangan kearah individualitas yang mantap dan berdiri sendiri. Kemandirian seorang anak pada hakikatnya tidak bersifat tunggal tetapi jamak. Artinya, seseorang dikatakan mandiri tidak hanya dilihat dari satu aspek semata, tetapi juga dari aspek lain seperti fisik, moral, sosial, emosional, dimana kemandirian merupakan pintu gerbang menuju kedewasaan seseorang. Menurut Reni Akbar (2001) dalam (Komala, 2015) Mandiri berarti anak yang kreativitasnya baik, untuk itu guru diperlukan kemampuan untuk menciptakan suasana belajar yang merangsang anak lebih ingin mengetahui materi pembelajaran, senang bertanya, dan berani mengajukan pendapat serta melakukan percobaan yang menuntut pengalaman baru.

Anak yang mandiri percaya terhadap penilaian sendiri, sehingga tidak sedikit-sedikit bertanya atau meminta bantuan. Anak yang mandiri memiliki control yang lebih baik terhadap kehidupannya. Menurut Havinghurst (Mu'tadin, Komala, 2015) kemandirian dalam konteks individu memiliki aspek yang lebih luas dari sekedar aspek fisik, yaitu: aspek emosi ditunjukan dengan kemampuan mengontrol emosi, aspek ekonomi ditunjukan dengan kemampuan mengatur ekonomi dan tidak tergantung kebutuhan ekonomi pada orangtua, aspek intelektual ditunjukan dengan kemampuan mengatasi berbagai masalah yang dihadapi dan aspek sosial ditunjukn dengan kemampuan interaksi dengan orang lain. Anak yang sudah mandiri dan dapat memanfaatkan lingkungan untuk belajar, dapat membatu anak lain untuk belajar mandiri. Anak harus tau apa saja yang dapat mereka lakukan dengan keberadaan lingkungan yang dapat dimanfaatkannya. Dengan begitu anak dapat mengidentifikasi lingkungan yang mana yang tepat dan sesuai dengan kebutuhan anak yang pada akhirnya anak akan memiliki perilaku dan kemampuan bertanggung jawab, dapat mengatasi masalah, dapat mengendalikan emosi, mau saling berbagi, empati terhadap orang lain.

\section{E. Ciri-Ciri Kemandirian}

Menurut Yamin \& Sabri (2013) anak yang mandiri untuk ukuran anak usia dini terlihat dengan ciri-ciri:

1. Dapat melakukan segala aktivitasnya secara sendiri meskipun tanpa diawasi oleh orang tua. 
Lusi Nuranisa, Mesi Triani, Wida Austin Hidayah, Putri Mei Aurelia, Dede Anwar Sanusi, Nunik Nasyatul Khoeriyah, Elfan Fanhas Fatwa Khomaeny. PUZZLE SEBAGAI MEDIA BERMAIN UNTUK MELATIH KEMANDIRIAN ANAK USIA DINI. Early Childhood Vol. 2 No. 2a, November 2018

2. Dapat membuat keputusan dan pilihan sesuai dengan pandangan, pandangan itu sendiri diperoleh dari melihat perilaku atau perbuatan orang-orang yang disekitarnya.

3. Dapat bersosialisasi degan orang lain tanpa perlu ditemani orang tua.

4. Dapat mengontrol emosinya bahkan dapat berempati terhadap orang lain.

Covey menegaskan bahwa kemandirian memiliki ciri-ciri diantaranya: 1) secara fisik mampu bekerja sendiri, 2) secara mental dapat berfikir sendiri, 3) secara kreatif mampu mengekspresikan gagasannya dengan cara yang mudah dipahami, dan 4) secara emosional kegiatan yang dilakukannya dipertanggung jawabkan sendiri.

\section{F. Faktor-Faktor Kemandirian}

Faktor-faktor yang mempengaruhi perkembangan kemandirian anak usia dini terbagi menjadi 2 yaitu:

1. Faktor internal adalah faktor yang ada dari diri anak itu sendiri yang meliputi:

a) Emosi, faktor ini ditunjukan dengan kemampuan mengontrol emosi dan tidak tergantungnya kebutuhan emosi dari orangtua.

b) Intelektual, faktor ini ditunjukan denga kemampuan untuk mengatasi berbaga masalah yang dihadapi.

a. Faktor eksternal adalah hal-hal yang datang atau ada dari luar diri anak itu sendiri yaitu meliputi lingkungan, karakteristik sosial, stimulus, pola asuh, cinta dan kasih sayang, kualitas interaksi anak dan orang tua, pendidikan orang tua.

\section{G. Bentuk-Bentuk Kemandirian}

Menurut Steinberg (dalam Desmita, 2011) dibedakan kemandirian anak menjadi tiga bentuk, yaitu:

1. Kemandirian emosi, yaitu aspek kemandirian yang berhubungan perubahan kedekatan atau keterikatan hubungan emosional individu, terutama dengan orangtua atau orang dewasa lainnya yang banyak melakukan interaksi dengannya. Contoh kemandirian emosi diantaranya yaitu hubungan antara anak dengan orangtua berubah sangat cepat, terlebihnya lagi setelah anak menginjak masa remajaseiring dengan semakin mandirinya anak dalam mengurus diri sendiri pada pertengahan masa kanak-kanak, maka perhatian orangtua dan orang dewasa lainnya terhadap anak semakin berkurang.

2. Kemandirian kognitif, yaitu mandiri dalam bertindak dan bebas untuk bertindak sendiri tanpa terlalu bergantung pada orang lain.

3. Kemandirian nilai, yaitu kebebasan anak memaknai seperangkat benarsalah, baik-buruk apa yag berguna bagi dirinya.

\section{H. Pengertian Bermain}

Permainan adalah salah satu bentuk aktivitas sosial yang dominan pada awal masa anak-anak. Sebab anakanak menghabiskan lebih banyak waktunya di luar rumah bermain dnegan teman-temannya dibanding terlibat dalam aktivitas lain. Sedangkan bermain dalam Kamus Besar Bahasa Indonesia di artikan sebagai proses 
Lusi Nuranisa, Mesi Triani, Wida Austin Hidayah, Putri Mei Aurelia, Dede Anwar Sanusi, Nunik Nasyatul Khoeriyah, Elfan Fanhas Fatwa Khomaeny. PUZZLE SEBAGAI MEDIA BERMAIN UNTUK MELATIH KEMANDIRIAN ANAK USIA DINI. Early Childhood Vol. 2 No. 2a, November 2018

melakukan sesuatu untuk bersenangsenang.

Menurut Hurlock (Fauziddin, 2017:10) bermain merupakan suatu kegiatan yang dilakukan oleh anak dengan spontan, perasaan gembira, tidak memiliki tujuan ekstrinsik, melibatkan peran aktif anak, memiliki hubungan sistematik dengan hal - hal di luar bermain seperti perkembangan kreativitas, dan merupakan interaksi antara anak dengan lingkungannya, serta memungkinkan anak untuk beradaptasi dengan lingkungan tersebut. Bermaian bagi anak sangat membantu dalam proses pengembangan aspek sosial, kognitif dan emosinya.

\section{Jenis-Jenis Bermain}

Bermain dapat digambarkan dalam suatu kontinum yang berawal dari bermain bebas, bemain dengan pedoman atau terarah menuju bermain terarah.

1. Free play (bermain bebas), yaitu suatu aktivitas bermain dimana anakanak memiliki kebebasan dalam memilih berbagai benda/alat permainan yang tersedia dan mereka dapat memillih bagaimana menggunakan alat tersebut.

2. Guide play (bermain terpimpin), yaitu suatu aktivitas bemain dimana guru memiliki peranan dala memilih material atau alat bermain yang sesuai dengan berbagai konsep.

3. Directed play (bermain terarah), yaitu aktivitas bermain dimana guru meminta/memeintahkan anak-anak dalam rangka bagaimana menyelesaikan tugas-tugas khusus.

\section{J. Fungsi Bermain}

Menurut beberapa tokoh, bermaian memiliki beberapa fungsi yaitu :

1. Sigmund freud dengan teory psychoanalytiknya

Bermain berfungsi untuk mengekspresikan dorongan impulsif sebagai cara untuk mengurangi kecemasan yang berlebihan pada anak, melalui bermain dan berfantasi anak dapat mengemukakan harapan-harapan dan konflik serta pengalaman yang tidak dapat diwujudkan dikehidupan nyatanya.

2. Jean piaget (teori cognitive development)

Bermain mampu mengaktifkan otak kanan, megintegrasikan fngsi otak kanan dan kiri secara seimbnag dan membentuk struktur sarap, serta mengembangkan pilarpilar saraf pemahaman yang berguna untuk masa mendatang.

3. Vigotsky

Bermain mampu mengembangkan aspek sosial dan perkembangan kognitif anak. Karena pertamatama anak akan menemukan pengetahuan dalam dunia soaialnya kemudian enjadi bagian dari perkembangan kognitifnya.

Berdasarkan kajian tersebut bermain dapat mengembangkan aspek perkembangan anak. Sosial emosional anak berkembang melalui bermain dan akan menumbuhkan rasa memiliki, bertumbuhnya rasa percaya diri, belajar untuk hidup mandiri, dan bekerja sama dalam kelompok dengan segala perbedaan. 
Lusi Nuranisa, Mesi Triani, Wida Austin Hidayah, Putri Mei Aurelia, Dede Anwar Sanusi, Nunik Nasyatul Khoeriyah, Elfan Fanhas Fatwa Khomaeny. PUZZLE SEBAGAI MEDIA BERMAIN UNTUK MELATIH KEMANDIRIAN ANAK USIA DINI. Early Childhood Vol. 2 No. 2a, November 2018

Aspek kognitif berkembang pada saat bermain, yaitu anak mampu meningkatkan perhatian dan konsentrasinya, mampu memunculkan kreativitas, mampu berpikir divergen, melatih ingatan, mengembangkan perspektif, dan mengembangkan kemampuan berbahasa. Konsep abstrak yang membutuhkan kemampuan kognitif juga terbentuk melalui bermain, dan terrealisasikan kedalam kehiduap sehari-hari anak, sehigga anak mampu memahami dunia di sekitarnya.

\section{K. Bermain Puzzle}

Menurut Oguzkan \& Avci (2000, dalam Aral, 2012) dengan menyelesaikan puzzle secara individual, anak-anak akan mendapatkan beberapa keterampilan seperti melakukan aktivitas selama waktu tertentu, berbagi, kerjasama, menunggu giliran mereka, mematuhi aturan, konsentrasi, kepercayaan diri, pengaturan diri, rasa hormat untuk orang lain dan keterampilan mendengarkan. Bermain puzzle yang dilakukan secara berkelompok membantu anak dalam mengembangkan kemampuan bersosialisasi melalui kerjasama satu sama lain dan usaha anak untuk menyelesaikan tugas permainan puzzle sendiri akan membantu anak mengembangkan kemampuan kemandirian dalam menyelesaikan masalah. Menurut Sunarti (2005) permainan puzzle mempunyai tujuan mengenalkan anak beberapa strategi sederhana dalam menyelesaikan masalah, melatih kecepatan, kecermatan, dan ketelitian dalam menyelesaikan masalah, dan menanamkan sikap pantang menyerah dalam menghadapi masalah.

Penerapan menggunakan media puzzle dalam proses pembelajaran akan menstimulus anak untuk ikut aktif dalam pembelajaran. Adapun manfaat puzzle menurut Hamalik (2001) dapat meningkatkan perhatian anak dalam proses pembelajaran, suasana kelas menjadi aktif, dan menumbuhkan pemikiran yang teratur melalui gambar.

Anak usia dini merupakan manusia yang sedang dalam proses pertumbuhan menuju kedewasaan. Oleh karenanya pendidikan pada anak usia dini harus sudah mulai diterapkan, salah satu contoh pendidikan karakter kemandirian. Kemandirian akan membuat anak menjadi mandiri atau tidak tergantung pada orang lain dalam melakukan sesuatu yang ingin dia lakukan. Penerapan pendidikan karakter pada anak haruslah sesuai dengan perkembangan anak. Sebagai manusia yang dewasa, orang tua tidak boleh memaksa anaknya dalam hal mendidik, karena pola asuh orang tua akan menentukan kehidupannya di masa yang akan datang. Penerapan pendidikan karakter bisa dilaksanakan dengan metode puzzle, karena media puzzle juga dapat menstimulus anak lebih aktif mengikuti pembelajaran, warna dan potongan gambar yang bervariasi, memudahkan dalam menyampaikan materi.

Salah satu contoh puzzle yang bisa digunakan dalam melatih kemandirian yaitu puzzle dom, dimana permainan tersebut tidak membosankan, 
Lusi Nuranisa, Mesi Triani, Wida Austin Hidayah, Putri Mei Aurelia, Dede Anwar Sanusi, Nunik Nasyatul Khoeriyah, Elfan Fanhas Fatwa Khomaeny. PUZZLE SEBAGAI MEDIA BERMAIN UNTUK MELATIH KEMANDIRIAN ANAK USIA DINI. Early Childhood Vol. 2 No. 2a, November 2018

banyak bentuk permainannya, diantaranya: (a) connect yaitu permainan sederhana yang menghubungkan titik-titik dengan warna yang sama. (b) blocks yaitu tekateki klasik yang mengisi seluruh papan dengan bentuk yang berbeda blocks. (c) rolling ball yaitu permainan dengan membuat jalur agar bola bisa mencapai titik finish.

Permainan ini cocok untuk anak usia dini karena permainan ini dapat di akses melalui smartphone. Dengan permainan puzzle ini anak akan berusaha untuk menyelesaikan satu persatu jenis permainan yang ada di permainan ini karena permainannya sangat mudah dan bertahap dan juga ada bantuan untuk anak agar bisa menyelesaikan permainanya tetapi bantuan itu tidak selamanya bisa digunakan oleh anak karena bersifat terbatas. Oleh karena itu, bermain dengan menggunkan permainan ini akan mengajarkan anak untuk tidak tergantung pada bantuan orang lain melainkan harus selalu berusaha untuk menyelesaikannnya sendiri dan juga anak akan bisa mengontrol emosinya dengan baik.

\section{SIMPULAN}

Permainan Puzzel adalah permainan yang disenangi oleh anak usia dini, terlebih permainan tersebut dalam bentuk aplikasi yang ada pada smartphone. Permainan puzzel dapat meningkatkan kemandiri anak, karena dengan permainan puzzle ini anak akan berusaha untuk menyelesaikan satu persatu jenis permainan yang ada di permainan ini, karena permainannya sangat mudah dan bertahap dan juga ada bantuan untuk anak agar dapat menyelesaikan permainannya, tetapi bantuan itu tidak selamanya bisa digunakan oleh anak karena bersifat terbatas. Oleh karena itu, bermain dengan menggunakan permainan ini akan mengajarkan anak untuk tidak tergantung pada bantuan orang lain, melainkan harus selalu berusaha untuk menyelesaikannnya sendiri dan juga anak dilatih untuk mengontrol emosinya dengan baik.

\section{DAFTAR PUSTAKA}

Desmita.(2011).

Psikologi

Perkembangan Peserta

Didik. Bandung: PT Remaja

Rosdakarya.

Desmita.(2016).

Psikologi

Perkembangan. Bandung: PT Remaja Rosdakarya.

Priyanto, Aris.(2014). Pengembangan Kreativitas Pada Anak Usia Dini Melalui Aktivitas Bermain. Jurnal Ilmiah Guru "COPE". No 2.

Elfan Fanhas F Kh, Gina Nurazizah Mukhlis. Pendidikan Karaktek Untuk Anak Usia Dini Menurut Q.S. Lukman : 13-19. PEDAGOGI: Jurnal Anak Usia Dini dan Pendidikan Anak Usia Dini Volume 3 Nomor $3 \mathrm{a}$ Desember 2017

Fauziddin,Muhammad.(2014).Pembelaj aran PAUD. Bandung: PT. Remaja Rosdakarya. 
Lusi Nuranisa, Mesi Triani, Wida Austin Hidayah, Putri Mei Aurelia, Dede Anwar Sanusi, Nunik Nasyatul Khoeriyah, Elfan Fanhas Fatwa Khomaeny. PUZZLE SEBAGAI MEDIA BERMAIN UNTUK MELATIH KEMANDIRIAN ANAK USIA DINI. Early Childhood Vol. 2 No. 2a, November 2018

Hasyim, Sukarno L.(2015). Pendidikan

Anak Usia Dini (PAUD)

Dalam Perspektif Islam.

Jurnal Lentera: Kajian

Keagamaan, Keilmuan dan

Teknologi Vol 1, No 2.

Hilmi, Ihsan. Nurlatifah, dkk.(2017).

Maket Kebun Binatang

Berbasis Limbah Industri

Rumahan Sebagai Media

Pembelajaran Untuk Anak

Usia Dini (AUD). Early

Chilhood:Jurnal Pendidikan.

Vol 1 No 1.

Juita, Ratna.(2012). Peningkatan

Kemampuan Berhitung Anak

Melalui Permainan Menakar

Air Di Tk Aisyiyah Koto

Kaciak Maninjau. Jurnal

Pesona PAUD. Vol 1.

Kartono. Kartini.(2007). Psikologi

Anak. Bandung: CV. Mandar

Maju.

Khasanah,

Ismatul,

Dkk.(2011). Permainan

Tradisional Sebagai Media

Stimulasi. Jurnal Penelitian

PAUDIA. Volume 1 No. 1

Komala.(2015). Mengenal dan

Mengembangkan

Kemandirian Anak Usia Dini

Melalui Pola Asuh Orang

Tua dan Guru. Jurnal Tunas

Siliwangi. Nomor: 01. Vol.

01.

Latif, Mukhtar, dkk.(2013). Orientasi

Baru Pendidikan Anak Usia

Dini. Jakarta: Kencana

Prenada Media Grup.

Mulyadi, Seto dkk. (2016). Psikologi

Pendidikan dengan
Pendekatan Teori-Teori Baru dalam Psikologi. Jakarta: PT RajaGrafindo Persada.

Putra, K Dwi dan Jannah Miftakhul.(2013). Perkemban gan Kemandirian Anak Usia Dini (Usia 4-6 tahun) Di Taman Kanak-Kanak Assalam Surabaya. Nomor; 03. Vol 01.

Selvie. (2012). Menulis Studi Literatur. http://shelvie.staff.ipb.ac.id/2 $\underline{012 / 05 / 11 / m e n u l i s-s t u d i-}$ literatur/.

Setyaningsih, Tunggul Sri Agus dan

Wahyuni, Hesti. (2018).

Stimulasi Permainan Puzzle

Berpengaruh Terhadap

Perkembangan Sosial dan

Kemandirian Anak Usia

Prasekolah. Jurnal

Keperawatan Silampari

(JKS). Vol 1, No 2.

Sujiono, Yuliani Nurani.(2012). Konsep

Dasar Pendidikan Anak Usia

Dini. Jakarta: PT Indeks.

Sya'diah, Rika.(2017). Pentingnya

Melatih Kemandirian

Anak. Jurnal KORDINAT.

No 01. Vol XVI.

[online] tersedia di http://digilib.unila.ac.id/916/10/B AB\%203.pdf 